\title{
Spatio-temporal Analysis and Assessment of High- Temperature Heat Wave Disaster Risk in Chengdu
}

\author{
Bin Huang ${ }^{1}$, Bingwei Tian ${ }^{*}, 1,2$, Ling Wang ${ }^{3}$, Shiyao Gu ${ }^{1}$, Feiyu Chen ${ }^{1}$ \\ 1 Institute for Disaster Management and Reconstruction Sichuan University-The Hong Kong Polytechnic University. \\ 2 West China Hospital/West China Hospital of Medicine, Sichuan University \\ 3 Key Lab of Land Resources Evaluation and Monitoring in Southwest, Ministry of Education, Sichuan Normal University \\ Chengdu 610207, China \\ bwtian@scu.edu.cn
}

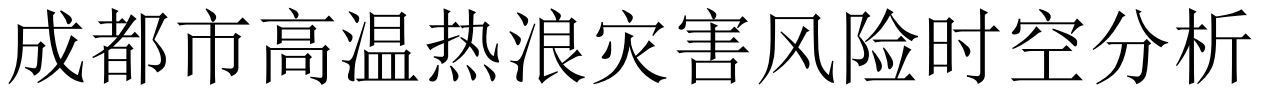

\author{
黄斌 ${ }^{1}$ 田兵伟 ${ }^{*}, 1,2$ 王玲 ${ }^{3}$ 顾诗瑶 ${ }^{1}$ 陈飞宇 ${ }^{1}$ \\ 1 四川大学-香港理工大学 灾后重建与管理学院 \\ 2 四川大学华西医院/华西临床医学院 \\ 3 四川师范大学 西南土地资源评价与监测教育部重点实验室 \\ 成都 610207，中国 \\ bwtian@scu.edu.cn
}

\begin{abstract}
With Global warming and rapid urbanization, the heat island effect is intensified, extreme meteorological disasters caused by atmospheric circulation anomalies continue to intensify. High-temperature heat wave (HTHW) disaster caused death, drought, fires, grain reduction, water and electricity supply shortages in many countries. Therefore, it is a high need to assessment the risk of urban HTHW disaster, and put forward measures for disaster prevention and mitigation of urban HTHW disaster. In this study, we use Landsat 8 image to retrieve the land surface temperature (LST) by the radiative transfer equation algorithm. Based on literature review, case comparison and analytic hierarchy process (AHP), three feature layers of disaster stress (B1), disaster vulnerability (B2), and disaster adaptation ability (B3) were selected. 10 indicator layers from the perspective of society, economy and thermal environment were selected for computation. Based on the spatial distribution of LST in Chengdu, we established a risk assessment framework for HTHW disaster assessment in Chengdu. Combination with $R$ language and GIS natural discontinuity point method, analysis of the spatio-temporal variation characteristics of the risk of HTHW disaster in Chengdu. We conclude that: 1 . The LST of Chengdu has a regular increase and decrease with the relative distance between the central city and the mountains, showing a significant urban heat island phenomenon. 2. The LST of Chengdu has a spatial distribution of "two basins separated by two mountains". The time series of HTHW have fluctuating characteristics of "enhancement-subtraction-enhancement" and three variations: "continuous reduction", "period falling back" and "continuous increasing". 3. The extreme difference between the HTHWCRI is large, indicating that the polarization of the HTHW risk in Chengdu is serious. 4. The high-temperature heat wave risk factor layer mainly has three models of "low-high-low", "high-low-high" and "high-highlow", and there is a clear positive between high temperature heat wave stress and high temperature heat wave risk. Positive correlation between relevance, socio-economic development level and regional disaster adaptive capacity. 5. Jintang district
\end{abstract}

has obvious "enclave" characteristics in the intensity and risk of HTHW. The number of HTHW continues to increase and the risk of HTHW is high.

Keywords-high-temperature heat wave (HTHW), disaster risk, land surface temperature (LST), spatial zoning, spatiotemporal analysis

摘要一全球气候变暖、城市热岛效应及大气环流异常引起 的极端气象灾害不断加剧, 导致高温热浪灾害频发, 并在我 国以及世界各地引起的人员死亡、健康损害、干旱缺水、粮 食减产、森林火灾、水电供应等事件呈现增多趋势。因此, 对城市高温热浪灾害风险进行评估并提出城市高温防治措施 十分必要且紧迫。本文利用 Landsat 8 数据, 通过辐射传输 方程法反演地表温度, 基于文献综述、案例对比、层次分析 法选取灾害胁迫 (B1) 、灾害脆弱性 (B2)、灾害适应能力 (B3) 3 个要素层, 从社会、经济、热环境角度选取 10 个指标 层, 在明确成都市温度场空间分布特征的基础上, 建立成都 市高温热浪灾害风险评估框架。利用 $\mathrm{R}$ 语言结合 GIS 自然间 断点法分析了成都市高温热浪灾害风险时空变化特征。主要 结论: 1. 成都市地表温度以中心城区、山脉的相对距离有规 律增减, 表现出明显的城市热岛现象; 2 . 成都市地表温度呈 “两山隔两盆” 的空间分布特征、“增强一骤减一增强” 的 波动型时间变化特征, 时间序列有 “持续减少”、“期间回 落”、“持续增强”三种变化规律; 3 . 高温热浪综合风险指 数极值差较大, 表明成都市整体高温热浪风险的两极分化情 况严重; 4. 高温热浪风险要素层主要有 “低-高-低”、“高 一低-高”、“高-高-低” 3 种组合模式, 且高温热浪胁迫与高 温热浪风险之间有明显的正向相关性, 社会经济发展水平与 区域灾害适应能力的正向相关性; 5. 金堂县的高温热浪强度 和风险表现出明显的 “飞地” 特征, 高温热浪日数持续增多 且高温热浪常年处于高风险状态。 
引言

IPCC 第五次评估报告计算结果表明: 21 世纪地表温 度上升趋势明显, 热浪发生的频率更高、时间更长 $[1]$ 。 2018 年 3 月, 世界气象组织 (WMO) 发布的《2017 年 全球气候状况声明》指出: 全球最热的 5 年从 2010 年开 始, 2013 至 2017 年这 5 年全球均温达到有记录以来的 最高值[2]; 2019 年 2 月 6 日, 美国国家海洋与大气管理 局（NOAA）国家环境信息中心（NCEI）发布《2018 年 度全球气候报告》指出: 2018 年成为自 1880 年有记录 以来的第四热年，其中排名前 3 热年分别为 2016、2015、 $2017,2015-2018$ 年成为连续的最热 4 年期; 全球增温趋 势显著。高温热浪极端气候事件与死亡率升高、疾病、 暴力行为、干旱、森林火灾、龙卷风、农业和畜牧业生 产力下降、建筑和运输困难以及电力供应紧张都密切相 关[3]; 对人类健康的影响包括心血管疾病死亡率、因热 浪而引起的呼吸系统疾病、传染病的传播等 [4], 已被公 认为世界性的公共卫生问题[5]。

世界气候研究计划 WCRP (World Climate Research Programme) 明确提出: 极端高温热浪属于全球面临的巨 大气候挑战之一。1995 年, 芝加哥高温热浪灾害造成 739 人因过热死亡和至少 3300 例急诊病例, 其中 $82 \%$ 为 75 岁及以上老人[6-7]; 2006 年川渝地区遭受 50-100 年 一遇的特大高温干旱, 导致直接经济损失达 210 多亿元, 期间重庆市綦江最高气温达 $44.5^{\circ} \mathrm{C}$; 2018 年 7 月, 加拿 大东部的鬼北克省最高气温飙升至 $40^{\circ} \mathrm{C}$ 以上, 造成 70 余人死于炎热导致的并发症, 其中大多数为 60 岁以上的 慢性疾病患者。1995 年的芝加哥、2003 年的欧洲、2010 年的俄罗斯等时等地的重大热浪灾害事件, 造成了热相 关死亡率突增、超额死亡明显等一系列灾害性较大的影 响。通过对历史热浪灾害事件的发展过程、造成结果、 形成原因等进行梳理与总结得出以下 5 点结论: 1 . 全球 气候变暖显著: 21 世纪后, 特别是 2005 年以后, 全球 性的气候变化造成高温热浪时间的发生频率、持续时间、 强度等都有明显增强, 且未来将更加严重且频繁; 2. 风 险特征: 高温热浪灾害不仅有时间上的突发性、持续性, 也包括地点、程度等的不确定和难以预防等特点; 3. 危 害性: 城市人口老龄化加剧, 高温热浪灾害对人类健康 及生命的威胁与日俱增, 可在短时间内引起巨大且不易 挽回的伤亡事件; 4. 脆弱性群体: 老年、幼年、独居、 患病、低收入人群等更易受到影响; 5. 灾害响应: 政府 应对灾害的预警机制、应急响应能力、医疗急救服务完 善程度, 社会稳定程度等均与高温热浪灾害密切相关。

\section{研究区}

成都市位于四川省中部、四川盆地西部、岷江中游, 东经 $102^{\circ} 54^{\prime}-104^{\circ} 53^{\prime}$, 北纬 $30^{\circ} 05^{\prime}-31^{\circ} 26^{\prime}$ （图 1, 图 2）。亚热带季风性湿润气候, 夏季高温多 雨, 属于闷热性高温区域, 年平均气温在 $16^{\circ} \mathrm{C}$ 左右, 年平均日照时数为 $1042-1412 \mathrm{~h}$, 年均太阳辐射总量为 83.0-94.9 Km/ $\mathrm{cm}^{2}$, 据地表观测数据显示: 夏季日最高气 温出现在锦江区 2012 年 7 月 13 日 $45^{\circ} \mathrm{C}$ 。受西太平洋副 热带高压和青藏高原高压影响, 四川盆地的强高温现象 使其成为热浪灾害的脆弱性热点区域 [8-10], 易受高温热 浪灾害胁迫影响[11]。李双双等人通过趋势分析、空间 分析和相关性分析等方法对秦岭-淮河地区过去 56 年的 热浪时空变化特征进行分析, 指出四川盆地热浪

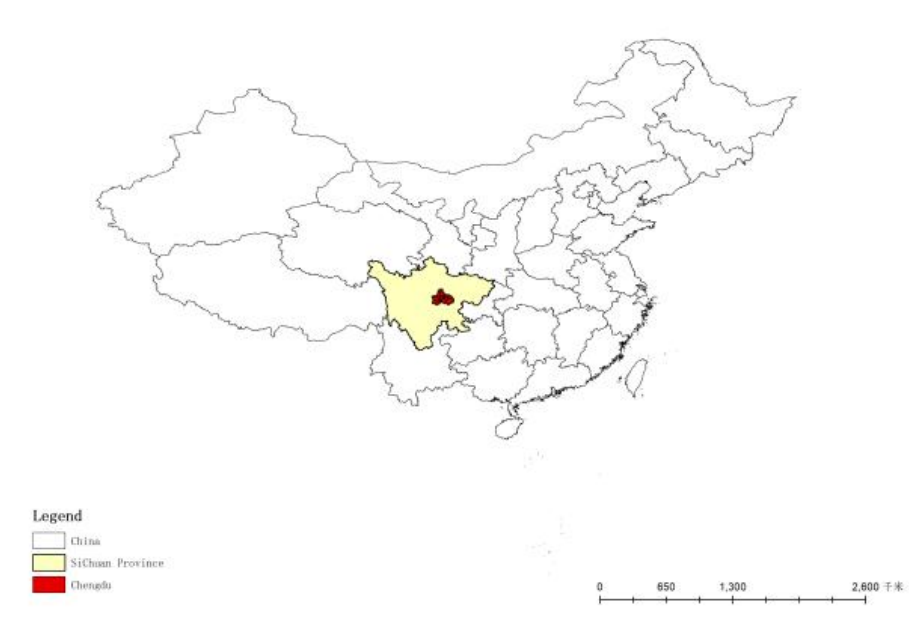

图 1 成都市区位图

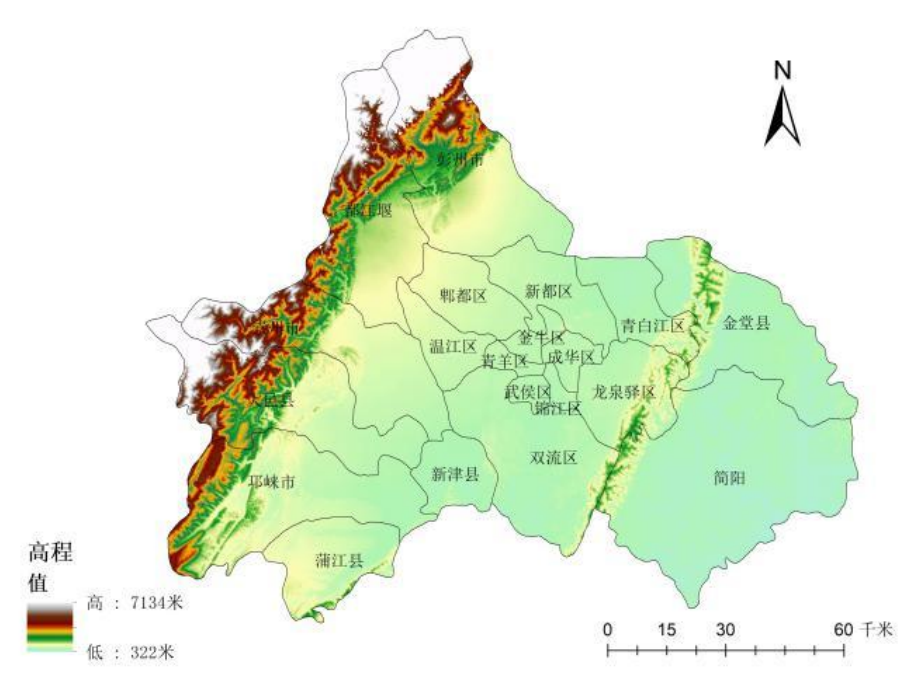

图 2 成都市地形图

呈 “高位波动” 现象, 且 $85.7 \%$ 的站点数据都表明四川 盆地的热浪上升态势明显 [12]; 通过对全国范围内 719 个基准站数据进行整理分析得出: 1993 年为全国整体增 温转折点, 西南地区高温热浪的爆发时间最早、增温速 度最快, 属于强高温热浪分布区域[8]; 通过分析全国高 温热浪的日数、频次、热浪指数的时空变化特征, 指出 高温日开始与结束的相对性关系, 即开始的早 (晚) 则 结束的就相对较晚 (早), 且 1998 年之后的长江以南地 区高温热浪发生频率较高[13]。

城市发展方面, 成都市作为四川省省会, 现辖 11 区 4 市 5 县, 另有管理和统计均单列的高新技术产业开发 区, 全市东西长 $192 \mathrm{~km}$, 南北宽 $166 \mathrm{~km}$, 面积 12121 $\mathrm{km}^{2}$ 。截至 2018 年末, 成都市辖区建成区面积达 885.6 $\mathrm{km}^{2}$, 常住人口达 1633 万人, 其中城镇人口 1194 万人, 市辖区城镇人口 917.5 万人, 全市城镇化率达 $73.12 \%$, 人口密度 3384 人 $/ \mathrm{km}^{2}$, 其中市区人口稠密, 高达 9611 人/ $\mathrm{km}^{2}$ 。2 2008-2018 年期间, 成都市的各项城市指标 变化情况如表 1 所示, 作为西南地区的科技、商贸、金 融中心和交通、通讯枢纽, 10 年时间里成都市的经济快 速增长, 城市规模迅速膨胀, 人口急剧增加, 是人口聚 集、经济发达、社会财富高度集中的超大城市。因此在 
遭受高温热浪灾害袭击时, 城市的高温热浪灾害胁迫和 脆弱性受到的威胁明显，导致社会财产及人类健康受到 的影响突出 [14]。目前, 针对成都市高温热浪的研究围 绕着热环境住宅舒适性、热岛效应时空变化及其与城市 发展之间的相关性等[15-16]，对高温热浪灾害本身的灾 害胁迫危险性、城市遭受灾害袭击时的脆弱程度、城市 应对高温热浪灾害的防灾减灾能力等的分析及评估依然 较少, 因此评估成都市高温热浪灾害风险, 是提升城市 高温热浪灾害的防灾减灾能力的基石[17]。

因此，本文确定研究时段为 2012-2016 年，以构建 “灾害胁迫一灾害脆弱性一灾害适应能力”这 3 个维度 的高温热浪脆弱性评估模型为研究结构 [18-20], 结合运 用 $3 \mathrm{~S}$ 技术与 $\mathrm{R}$ 软件对成都市的高温热浪灾害风险做定 量区划与监测 [21], 为高温防治措施的设定与实施提供 参考，以期提升成都市应对高温热浪的灾害韧性。

表 1 成都市主要城市指标统计数据

\begin{tabular}{cccc}
\hline 成都主要指标 & \multicolumn{2008}{c}{ 年 } & $\mathbf{2 0 1 6}$ 年 & $\mathbf{2 0 1 8}$ 年 \\
常住人口 & 1270.62 万人 & 1591.76 万人 & 1633 万人 \\
城镇化率 & $63.58 \%$ & $70.62 \%$ & $73.12 \%$ \\
建成区面积 & $427.65 \mathrm{~km}^{2}$ & $837.27 \mathrm{~km}^{2}$ & $931.6 \mathrm{~km}^{2}$ \\
建成区绿化覆盖率 & $38.58 \%$ & $41.39 \%$ & $41.7 \%$ \\
地区生产总值 & 3900.99 亿元 & 12170 亿元 & 15342.77 亿元 \\
\hline
\end{tabular}

数据来源

成都市 6-8 月 2012-2016 年日最高气温数据来源于成 都市气象局，其中锦江区、青羊区、金牛区、武侯区、 成华区、青白江区共计 6 个区市县，因未设有国家气象 站, 因此分别选用地方望江公园站、人民公园站、茶店 子站、双楠站、成都理工大学站、青白江区政府站作为 各区气温数据选用站点; 其余选用国家站点数据。

人口及社会经济数据来源于《四川省统计年鉴》、 《成都统计年鉴》、《成都市国民经济和社会发展统计 公报》、《武侯年鉴》、《成华年鉴》等。由于简阳市 2016 年才纳入成都市代管, 相关数据可获得性较低, 因 此本文未将简阳市纳入研究范围内。考虑条带缺失、精 度、时间范围等的要求，本文选取 Landsat 8 的 OLI、 TIRS10 数据进行地表温度（LST）的反演。

研究方法

采用辐射传输方程法实现地表温度的提取，在明确成 都市温度场空间分布规律的基础上，通过对已有研究及 典型极端气象灾害个案的总结分析, 结合成都市历年来 的高温热浪特点及城市发展现状，依据层次分析法分别 确定了灾害胁迫（B1）、灾害脆弱性(B2)、灾害适应能 力(B3) 3 个要素层, 从社会、经济、热环境角度选取 10 个指标层, 建立成都市高温热浪气象灾害风险评估框架。 运用 $\mathrm{R}$ 语言编写数据标准化方法和 AHP-熵值法综合赋 权法计算代码，确定各层次权重，计算城市高温气象灾 害综合风险指数（HTHWCRI）以确定成都市高温热浪 气象灾害风险, 运用 GIS 对成都市温度场及风险进行空 间区划，分析成都市 2012-2016 年间的高温热浪强度及 灾害风险的时空变化特征。

高温热浪灾害定义

世界气象组织（WMO）定义热浪为连续 3 天以上日 最高气温超过 $32^{\circ} \mathrm{C}$ 的天气事件; 荷兰、比利时、卢森堡
等国家采用荷兰皇家气象研究所对热浪的定义: 至少连 续 $5 \mathrm{~d}$ 日最高气温超过 $25^{\circ} \mathrm{C}$, 且期间至少有 $3 \mathrm{~d}$ 日最高气 温超过 $30^{\circ} \mathrm{C}$ 的天气; 丹麦定义热浪为至少连续 $3 \mathrm{~d}$, 其 中全国 $50 \%$ 以上的区域平均气温超过 $28^{\circ} \mathrm{C}$ 的天气; 瑞典 定义热浪为至少连续 $5 \mathrm{~d}$ 日最高气温超过 $25^{\circ} \mathrm{C}$ 的天气; 美国、加拿大、以色列等国通过预计白天热指数来判定 热浪的发生, 综合考虑了温度和相对湿度, 当预计白天 热指数连续 $2 \mathrm{~d}$ 有 $3 \mathrm{~h}$ 超过 $40.5^{\circ} \mathrm{C}$, 或者预计在任一时间 点超过 $46.5^{\circ} \mathrm{C}$ 时发布高温预警信息; 德国基于人体热浪 平衡模型制定了人体生理等效温度 ( PET: Physiologically Equivalent Temperature), 将人体生理等效 温度 $>41^{\circ} \mathrm{C}$ 作为高温热浪监测预警标准 [22]。我国高温 灾害被定义为由高温高湿而引起的人员、动植物不能适 应的异常天气现象, 国家气象局将高温热浪定义为持续 $3 \mathrm{~d}$ 以上且气温超过 $35^{\circ} \mathrm{C}$ 的天气过程[23-24]。

高温热浪属于持续性的异常高温天气，各国多以温度、 持续时间、人体感官等方面来判定高温热浪的发生, 仅 以表观的高温高热现象进行描述。由于高温热浪造成的 水电供应压力、中暑、死亡、疾病、森林火灾等均为直 接影响, 仍然存在例如农作物减产、建筑材料稳定性变 化等短时间内不易估量的间接影响[7], 因此对高温热浪 灾害的定义较难将其造成的影响一并纳入考虑范畴, 但 仅仅以热相关死亡对高温热浪灾害的影响进行研判, 必 定存在缺漏。因此本文选取我国对高温热浪的定义, 考 虑高温热浪强度及持续性特征, 选取了高温日数、高温 热浪日数作为灾害胁迫要素的分析指标, 综合城市高温 热浪灾害脆弱性、社会经济及基础设施等多方面的灾害 适应能力建立高温热浪灾害风险评估指标体系（表 2）, 以提升高温热浪灾害风险评估的科学性。

熵值法

区域权重:

$$
P_{i j}=\frac{r_{i j}}{\sum_{1}^{m} r_{i j}}
$$

信息熵: $E_{i j}=-k * \sum_{1}^{m} P_{i j} * \ln \left(P_{i j}\right), \quad k=\frac{1}{\ln (m)}$

信息效用熵:

$$
D_{i j}=1-E_{i j}
$$

权重:

$$
W_{i}=\frac{D_{i j}}{\sum_{1}^{n} D_{i j}}
$$

其中, $r_{i j}$ 为数据标准化计算结果所组成矩阵的参数, 根 据本文实际情况, $m=19$ (成都市所有区、市、县个数, 由于简阳市数据可获得性受限, 顾未计入), $n$ 为各准 则层层数。

辐射传输方程法

$$
\begin{gathered}
L_{s}=\left[\varepsilon B\left(T_{s}\right)+(1-\varepsilon) L L^{\downarrow}\right] \tau+L^{\uparrow} \\
L S T=\frac{K_{2}}{\ln \left[K_{1} /\left(B\left(T_{S}\right)+1\right)\right]}
\end{gathered}
$$

其中, LST 为地表温度, $\varepsilon$ 为地表辐射率, $\mathrm{T}_{\mathrm{s}}$ 为地表真 实温度, $\mathrm{B}\left(\mathrm{T}_{\mathrm{s}}\right)$ 为黑体辐射亮度, $\tau$ 为大气透过率, $\mathrm{L}^{\prime}$ 和 $\mathrm{L}^{\dagger}$ 分别为大气向下、向上辐射亮度; $\mathrm{K}_{1}=774.89$ 和 $\mathrm{K}_{2}=1321.08$ 为常量, 从元数据中查询获取。

高温热浪灾害综合风险指数

$$
\text { HTHWCRI }=\sum_{1}^{n} R * W r
$$

其中 $\mathrm{R}$ 为要素层 3 要素, $\mathrm{W}_{\mathrm{r}}$ 分别为各要素层对应的权重。 
表 2 成都市高温热浪气象灾害风险评估指标体系

\begin{tabular}{|c|c|c|c|c|}
\hline 准则层 & 要素层 & 指标层 & 指标计算 & 相关 \\
\hline \multirow{10}{*}{$\begin{array}{l}\text { 城市高 } \\
\text { 温热浪 } \\
\text { 气象灾 } \\
\text { 害脆弱 } \\
\text { 性 (A) }\end{array}$} & 灾害胁 & 高温日数（C1） & 日最高气温 $\geq 35^{\circ} \mathrm{C}$ 及以上日数 & + \\
\hline & 迫 & 高温热浪日数（C2） & 连续 $3 \mathrm{~d}$ 以上日最高气温 $\geq 35^{\circ} \mathrm{C}$ 的频数 & + \\
\hline & & 城市人口密度 (C3) & 区（市）县户籍人口/区（市）县建成 & + \\
\hline & & 中小学生人数比例 (C4) & 区 (市) 县中小学生人数/区 (市) 县户籍人口 & + \\
\hline & $\begin{array}{c}\text { 灭害肺 } \\
\text { 弱性 }\end{array}$ & 居民最低生活保障人数（C5） & $\begin{array}{l}\text { 区（市）县城市、农村居民最低生活保障年末人 } \\
\text { 数方和 }\end{array}$ & + \\
\hline & (B2) & 农林牧渔总产值占比（C6） & 区 (市) 县农林牧副渔业总产值/区域地方生产总 & + \\
\hline & 灾害适 & $\begin{array}{l}\text { 万人拥有医疗机构床位数 } \\
\text { (C7) }\end{array}$ & 区（市）县医疗机构床位数/区域户籍人口（万 & - \\
\hline & 应能力 & 万人拥有卫生技术人员（C8） & 区（市）县卫生技术人员/区域户籍人口（万人） & - \\
\hline & (B3) & 绿化覆盖率（C9） & 区（市）县绿化覆盖面积/区域建成区面积 & - \\
\hline & & 一般公共预算收入（C10） & 区（市）县一般公共预算收入 & - \\
\hline
\end{tabular}

高温热浪强度时间变化特征

采用我国对高温热浪的定义, 确定日最高气温高于 $35^{\circ} \mathrm{C}$ 为高温日, 持续 $3 \mathrm{~d}$ 且气温高于 $35^{\circ} \mathrm{C}$ 定义为高温热 浪, 基于 2012-2016 年 5 年时间内的地表气温观测数据 的统计, 得到如下图 3 所示时空变化过程:
2012-2016 年 6-8 月期间, 成都市的高温热浪总体呈 现 “增强一骤减一增强” 的波动型时间变化特征, 其中 2014 年大部分区域高温热浪日数整体突降, 高温热浪频 数甚至降低至 0 , 属于异常值。但受到全球气候变暖的 宏观趋势影响, 21 世纪之后, 特别是 2010 年开始, 成 都市整体高温热浪天气 5 年内出现不同程度的增多, 以

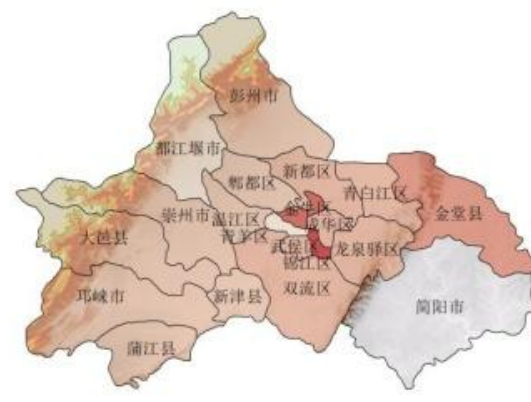

图 3a 成都市2012年高温热浪日数空间分布图

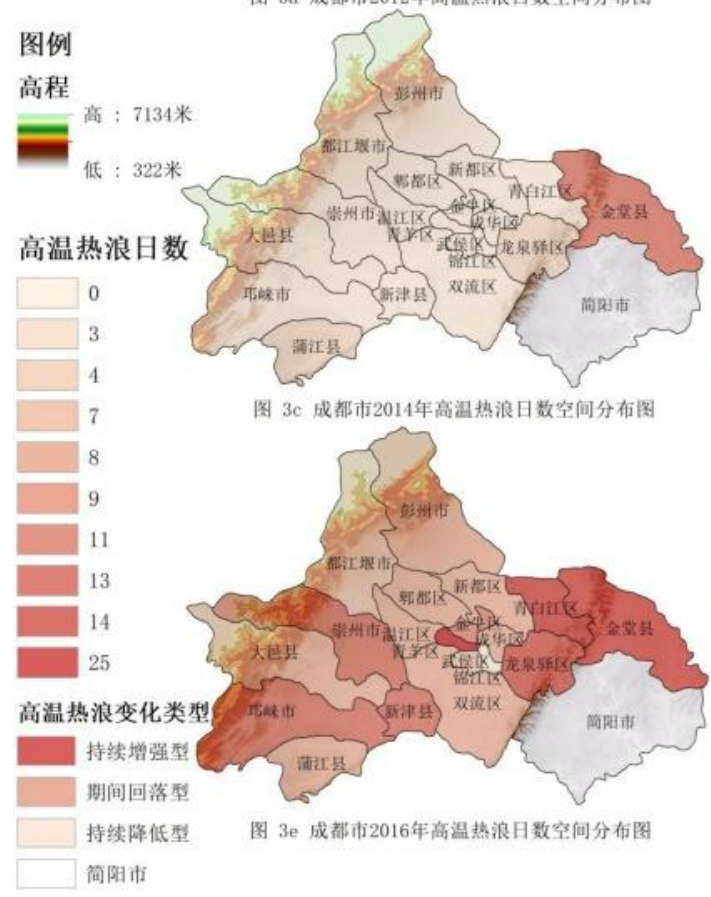

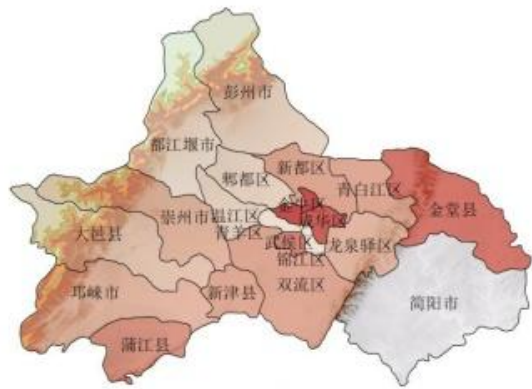

图 3b 成都市2013年高温热浪日数空间分布图
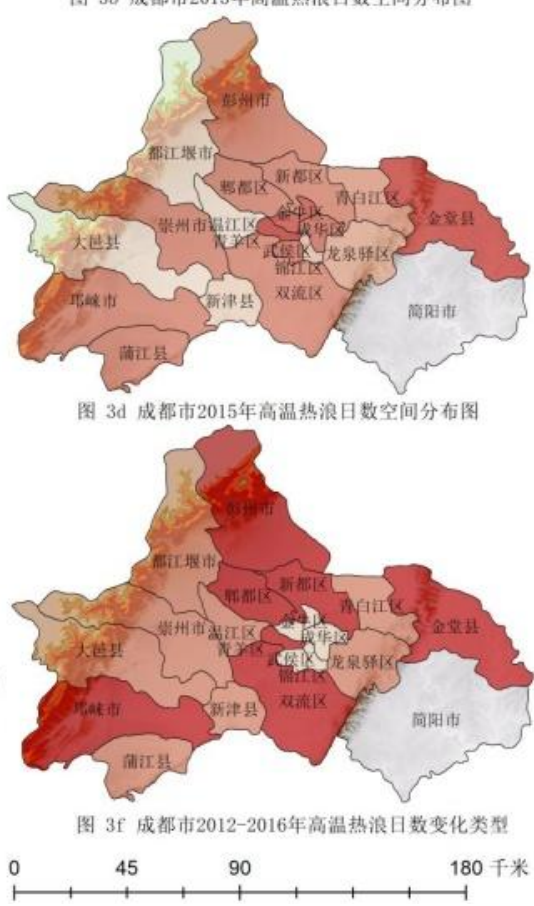

图 3 成都市高温热浪时空变化 
2012 年为起始值, 忽略 2014 年的异常值, 以 2016 年作 为上限值，根据成都市高温热浪时间序列动态变化过程， 将共计 19 个区市县的高温热浪变化情况分为 3 种类型, 其中心城区的高温热浪频数虽普遍居高, 但研究时段内 却逐年减少, 属于 “持续降低型” ; 如图所示, 相反南 北方向的区域及邛崃市、金堂县的高温热浪属于 “持续 增强型”; “期间回落型” 主要分布在东西方向, 到研 究时段未期的高温热浪日数都要于高于研究时段初期。

持续增强型：成都市南北方向的彭州市、郫都区、双
在地表温度反演过程中, 通过对 Landsat 8 的第 10 波 段进行辐射校准获取 DN 值; 构建元数据、NDVI、非监 督分类结果的多源数据; 基于 CART 算法的决策树自动 分类和像元二分模型估计植被覆盖度 (VFC: Vegetation Fractional Cover), 以此计算地表比辐射率, 并通过辐 射传输方程法反演地表温度。依据地表观测结果, 成都 在此两天的最大气温差为 $2^{\circ} \mathrm{C}$ 。因此, 在西部地区的地 表温度降低 $2^{\circ} \mathrm{C}$ 后, 两部分的温度以相同的颜色显示, 得到成都市整体地表温度反演结果, 如图 4 所示。

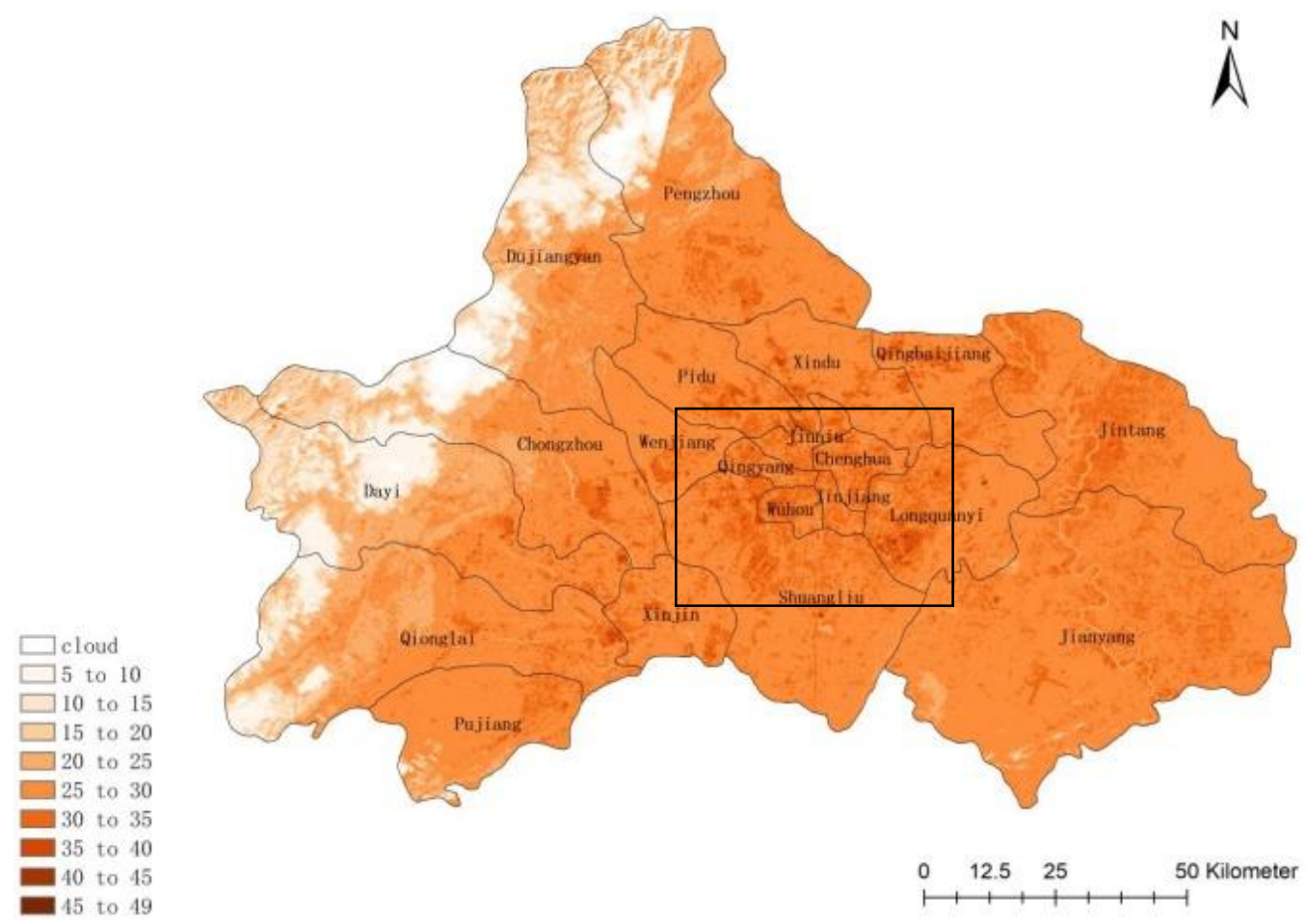

图 4 成都市地表温度遥感反演结果

流区、新都区与中心城区的青羊区、郊区的金堂县、扔 崃市共计 7 个区市县的高温热浪日数在研究时段内持续 增加;

期间回落型：成都市东西方向的崇州市、蒲江县、新 津县、大邑县、温江区、龙泉驿区、青白江区、都江堰 市共计 8 个区市县的高温热浪日数在 2014-2015 年期间, 先减弱后缓慢持续增强并超过初期水平;

持续降低型：成都市中心城区成华区、武侯区、金牛 区、锦江区共计 4 个中心城区的高温热浪日数从 2013 年 开始逐渐减少, 研究时段内高温热浪天气得到一定程度 的缓解。

\section{高温热浪强度空间分布特征}

由于 Landsat 8 数据覆盖整个成都市需要 129039、 129038、130039、130038 四幅影像，在保证时间一致性 的基础上, 本研究将成都分为东、西两部分进行地表温 度的反演。东部和西部地区的云覆盖率分别为 $0.18 \%$ 和 $7.82 \%$ 。但西部云覆盖区主要集中在龙门山脉带上, 对 分析建成区的影响不大, 因此西部的云覆盖区域地表温 度的跳跃可以忽略不计。
成都市西侧紧邻龙门山脉，东侧有龙泉山脉横梗其中， 山脉带海拔的走高, 使得其地表温度骤降, 低于周围平 原区域, 因此成都市地表温度呈 “两山隔两盆” 的空间 分布特征。以山脉带为区域分割线, 成都市中部地表温 度空间分布明显呈西低东高的 “城镇主导” 模式, 整体 的地表温度高温空间分布几乎严格按照城市形态的边界 为走向, 城镇用地区域地表温度明显高于周围区域, 且 越靠近主城区高温聚集现象越明显, 城市热岛效应越显 著。高温热浪灾害的无差别袭击造成明显的城市热岛效 应现象, 但中心城市的地表温度并不是最高, 超高温现 象发生在中心城市附近的次中心区域。这与城市内的植 被覆盖率、人口密度和建筑材料等密切相关, 但需要更 进一步的分析。

\section{高温热浪风险时空分布特点}

基于已建立的风险评估指标体系, 结合人口、社会经 济统计数据和气象站地表观测数据, 首先运用数据标准 化方法对各指标进行无量纲化, 消除指标间数值统计量 纲差异; 其后运用 AHP-熵值法综合赋权法计算准则层、 要素层、指标层权重, 利用 GIS 的自然段点法对成都市 高温热浪风险进行空间区划, 将高温热浪风险划分为低 风险、较低风险、中度风险、较高风险、高风险 5 个层 
次, 层次间隔点值分别为 $-0.3 、-0.1 、 0.1 、 0.3$; 并对灾 害胁迫、灾害脆弱性、灾害适应能力 3 个要素层的数量 关系以条形图的形式具象化, 得到图 5 所示结果。
部已基本没有山脉降温作用影响的骤变现象。这与成都 市高温热浪强度的时空变化趋势一致, 也与成都市 “东 进南拓”的空间发展格局相契合。
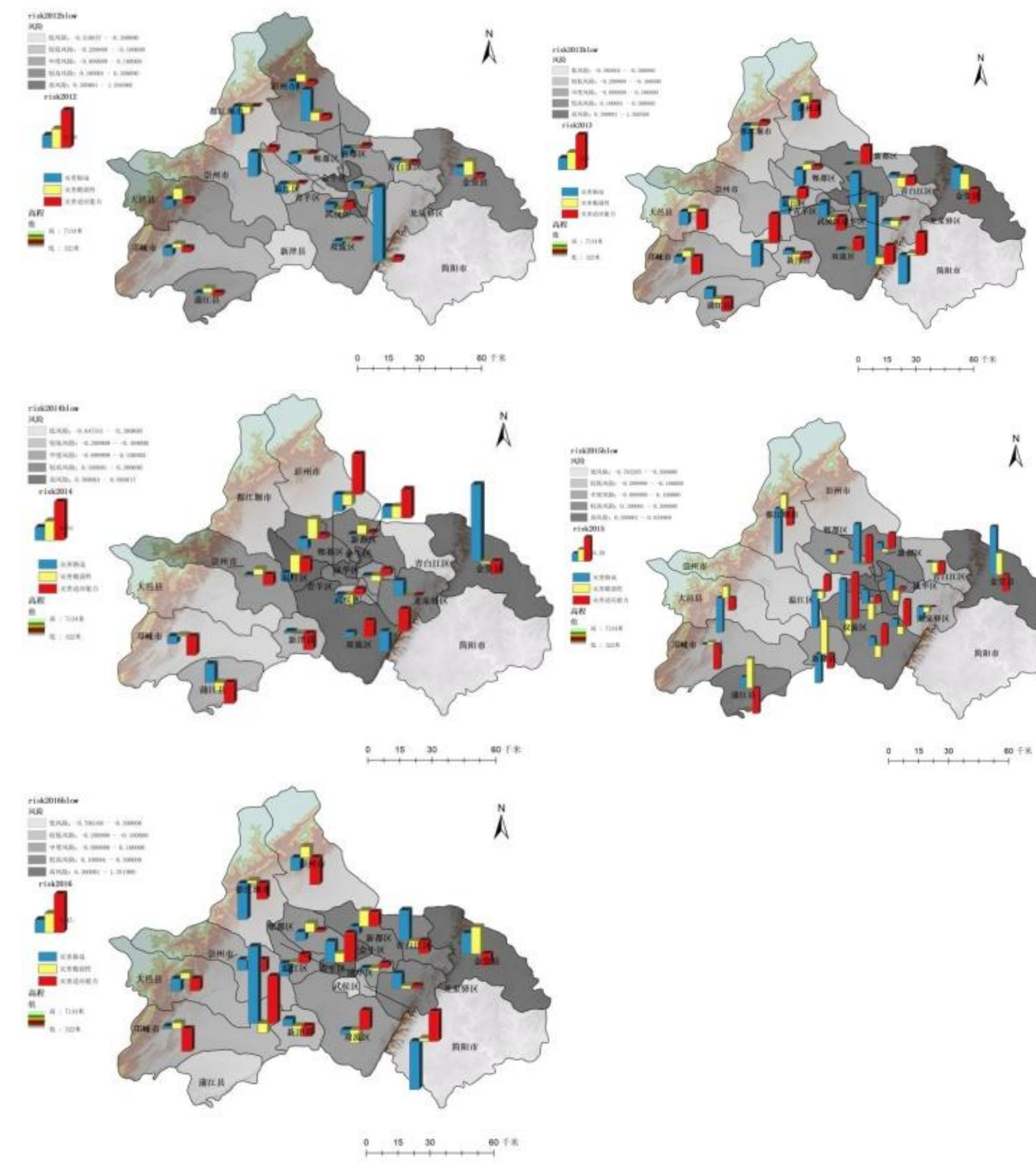

图 5 2012-2016 年成都市高温热浪风险等级图

结果表明: 各区域的风险极值差较大, 存在明显的两 极分化现象。高风险区域多集中在城市核心区域, 低风 险区域分散在周边。2012-2016 年间成都市高温热浪风 险在空间上有两次明显的趋势改变，总体可概括为 “分 散一集中一东西向分散” 的特点。2012-2015 年, 城市 高温热浪风险由摊大饼式的散漫分布特点, 逐步演化为 高风险区集中在城市核心区域; 2016 年，城市高温热浪 风险表现出 “东西向增强, 重心偏东” 的特征, 且中东
其中, 由于西部龙门山脉的影响, 成都市西部整体高 温热浪风险较低; 中部偏东有龙泉山脉间隔, 城市东部 的高温热浪风险有明显的跳跃变化特点, 但 2016 年该特 点不明显, 这与城市化程度的加深及 2016 年全球的极端 高温现象都有一定的相关性; 位于东北部的金堂县, 虽 与城市核心区域有龙泉山脉阻隔, 但高温热浪风险常年 居高且逐年增强, 表现出明显的高风险 “飞地” 现象。 
高温热浪风险要素层时空变化特征

就高温热浪风险各要素层的对比及分布情况来看, 灾 害胁迫-灾害脆弱性-灾害适应能力 3 个要素层的相对关 系主要有：“低-高-低”、“高-低-高”、“高-高-低” 3 种组合模式, 并且同一区域的要素层组合模式基本一 致。表现出高温热浪灾害风险的复杂性、多变性、综合 性，总结各区域要素层的显著特点有:

- 高温热浪灾害胁迫因子与高温热浪风险的正向 相关性：从 5 年整体风险等级来看，持续处于高风险状 态的武侯区、金牛区、金堂县的高温热浪灾害胁迫要素 明显偏高, 低风险区都江堰市、彭州市和较低风险区的 青羊区、温江区、郫都区等的灾害胁迫因素均为负值。

- 社会经济发展水平与区域灾害适应能力的正向 相关性: 金牛区、武侯区、成华区、青羊区、温江区等 老城区及周边临近区域的灾害适应能力均为正值, 且越 靠近城市核心区域适应能力越强, 与此相对应的城市郊 区区域，灾害适应能力相比较低，均为负向。

- 高温热浪风险 “飞地” : 研究时段内, 金堂县 高温热浪风险要素层相对关系始终为 “高-高-低”，区 域受到高温热浪灾害胁迫的影响力持续居高且灾害脆弱 性较高，但应对灾害的适应能力较低。因此区域高温热 浪风险常年居高, 与中心城区风险在同一等级。

\section{结论与讨论}

主要结论

2012－2016 年间，成都市高温热浪变化规律可划分 为持续增强型、持续降低型及期间回落型 3 类。中心城 区：成华区、武侯区、金牛区、锦江区共计 4 个区的高 温热浪日数居高, 但从 2013 年开始逐渐减少, 研究时段 内高温热浪天气得到一定程度的缓解, 属于高温热浪 “持续降低型”; 成都市南北方向的彭州市、郫都区、 双流区、新都区与中心城区的青羊区、郊区的金堂县、 邛崃市共计 7 个区市县的高温热浪日数在研究时段内持 续增加, 属于 “持续增强型”; 成都市东西方向的崇州市、 蒲江县、新津县、大邑县、温江区、龙泉驿区、青白江 区、都江堰市共计 8 个区市县的高温热浪日数在 20142015 年期间, 先减弱后缓慢持续增强并超过初期水平, 属于“期间回落型”。

以成都市中心城区为高温热浪核心区域, 周边区市县 点状成环分布, 地表温度以与城镇、山脉的相对距离两 种情况有规律增减, 表现出明显的 “城镇主导” 模式, 城市热岛效应显著。研究时段内成都市高温热浪呈现 “增强一骤减一增强” 的波动型时间变化特征; 另外, 由于成都市西部的龙门山脉和中部偏东的龙泉山脉的降 温作用，成都市地表温度整体呈 “两山隔两盆” 的空间 分布特征, 但次中心区域出现超高温现象, 中心城区地 表温度低于次中心区域。

2012-2016 年间的成都市高温热浪风险结果表明：成 都市高温热浪综合风险指数极值差较大，整体高温热浪 风险的两极分化情况严重; 成都市高温热浪风险在空间 上有明显的“分散一集中一东西向分散”变化趋势, 2016 年的高温热浪风险整体重心偏东且中东部已基本没有山 脉降温作用影响的骤变现象。其中，中心城区的金牛区 和城市东北部的金堂县风险常年偏高。
高温热浪风险要素层主要有“低-高-低”、“高-低-高”、 “高-高-低”3 种组合模式, 高温热浪胁迫与高温热浪风险 之间有明显的正向相关性, 社会经济发展水平与区域灾 害适应能力的正向相关性, 凸显出高温热浪的强度及持 续时间产生的灾害胁迫对高温热浪风险的加剧作用, 社 会经济能力的发展对高温热浪风险的缓解作用。

金堂县地表观气温数据统计结果与遥感数据反演结果 一致，表现出明显的高温热浪气象灾害“飞地”特征，与 同等级区域相比, 地表温度偏高, 灾害胁迫影响偏高; 受到城镇化率及社会经济发展情况的制约, 金堂县的高 温热浪灾害脆弱性偏高、区域灾害适应能力偏低, 区域 高温热浪综合风险指数居高不下，与金牛、青羊、锦江 等中心城区共同归属于同一风险等级, 属于高风险区域。

\section{对策与讨论}

城市中心区域社会经济发展状况良好, 因此建筑及人 口密度高, 在强高温热浪胁迫因素影响之下, 区域能够 投入更多的物资、医疗、救援等以响应防灾减灾, 区域 高温热浪灾害适应能力越强。成华区、武侯区等中心城 区高温热浪变化类型属于“持续降低型”，伴随着较低的 高温热浪风险, 但金牛区却为高风险区域, 说明随着城 市化的发展, 城市进行扩张的同时, 也要加大防灾减灾 能力的建设, 保证城市化与城市安全的协同发展, 促进 城市的可持续发展。

金堂县在高温热浪及风险的变化情况都表现出明显的 “飞地”现象，究其原因，金堂县作为川东北经济区的第 一门户，作为龙泉山东侧的现代制造业重要区域, 大力 发展的工业排热是影响区域高温热浪的关键要素之一。

研究中涉及到的指标数量及数据量都有限, 后期将对 指标的丰富度、适宜性、科学性做进一步研究, 以提升 该风险评估的科学有效性。

\section{致谢}

感谢四川大学灾后重建与管理学院第宝锋教授在论文 写作中给予讨论和意见。本项目得到国家重点研发计划: 公共安全风险防控与应急技术装备专项，航空应急救援 关键技术研究及应用示范项目, 课题 1: 航空应急救援 装备体系和标准体系研究项目资助（2016YFC0802600）, 特此感谢。

\section{参考文献}

[1] IPCC, 2014: 气候变化 2014: 综合报告, 政府间气候变化专门委员 会第五次评估报告第一工作组、第二工作组和第三工作组报告 [核心撰写小组、R.K. Pachauri 和 L.A. Meyer (eds.)], 瑞士日内瓦 IPCC, 共 151 页,

[2] 孙劭, 王东阶, 尹宜舟, 王国复, 柯宗建, “2017 年全球重大天气气 候事件及其成因”，气象, 2018.44 (4): 556 - 64.

[3] Delphine, Grynszpan., "Lessons from the French Heatwave", Lancet, 2003.362 (9391): $1169-70$.

[4] 王绍武, 赵宗慈, 罗勇, “IPCC 第 5 次评估报告问世”, 气候变化 研究进展, 2013.9 (6): 436 - 39.

[5] 王悦, 田申, 赵球平, 李旭东, “基于脆弱性的高温热浪天气适应能 力研究进展”, 环境与健康杂志, 2017. 34 (3): 278 - 81.

[6] Whitman. S, Good. G, Donoghue E R, Benbow N, Shou W, Mou S, "Mortality in Chicago Attributed to the July 1995 Heat Wave", American Journal of Public Health, 1997. 87 (9): 1515 - 8.

[7] 祁新华, 程煴, 李达谋, 金星星, 陈晔倩, “西方高温热浪研究述 评”, 生态学报, 2016.36 (9): $2773-8$. 
[8] 谢盼, 王仰麟, 彭建， “基于居民健康的城市高温热浪灾害脆弱性 评价——研究进展与框架”, 地理科学进展, 2015. 34 (2): 165 74.

[9] 贾佳, 胡泽勇, “中国不同等级高温热浪的时空分布特征及趋势”, 地球科学进展, 2017. 32 (5): 546 - 59.

[10] 谢盼, 王仰麟, 刘炎序, 彭建, “基于社会脆弱性的中国高温灾害人 群健康风险评价”, 地理学报, 2015.70 (7): 1041 - 51.

[11] Haines. A, Kovats R S, Campbell-Lendrum D, Corvalan C, "Climate Change and Human Health: Impacts, Vulnerability and Public Health.” Lancet, 2006. 120 (7): 585 - 96.

[12] 李双双, 延军平, 孔锋, 高文兰, 王娟, 赵怡, “极点对称模态分解下 西安高温天气的趋势特征”, 地理研究, 2018. 37 (1): 209 - 19.

[13] 沈皓俊, 游庆龙, 王朋岭, 孔否, “1961-2014 年中国高温热浪变 化特征分析”, 气象科学, 2018. No. 1.

[14] 赵春黎, 严岩, 陆咏晴, “基于暴露度-恢复力-敏感度的城市适应 气候变化能力评估与特征分析” , 生态学报, 2018. 38 (9): 250 59.

[15] 程志刚, 杨欣悦, 孙晨, 徐雅晋, “成都地区夏季城市热岛变化及其 与城市发展的关系”,气候变化研究进展, 2016. 12 (4): $322-31$.

[16] 张好, 徐涵秋, 李乐, “成都市热岛效应与城市空间发展关系分 析”, 地球信息科学学报, 2014. 16 (1): $70-78$.
[17] Bo Tang, Jinan Qiu, Jiaying Huang, Yuanyuan Zhang, Feipeng Qiu, Spatial and Temporal Patterns of Urban Vulnerability in Guangzhou, Journal of Risk Analysis and Crisis Response, 2019, 9(2): 101-110, https://doi.org/10.2991/jracr.k.190703.006.

[18] 蒋丽丽, “贫困脆弱性理论与政策研究新进展”, 经济学动态, 2017. 06: 98 - 110

[19] 郑雪梅, 王怡, 吴小影, 齐熙, 祁新华, “近 20 年福建省沿海与内陆 城市高温热浪脆弱性比较”, 地理科学进展, 2016. 35 (10): 1197 $-1205$.

[20] 张明顺，王义臣，“北京市高温热浪脆弱性评价”，城市与环境研 究, 2015. No. 1: 16 - 33 .

[21] Bingwei Tian., Wang, L., Kashiwaya, K., Koike K, Combination of Well- Logging Temperature and Thermal Remote Sensing for Characterization of Geothermal Resources in Hokkaido, Northern Japan. Remote Sensing, 2647-2667.

[22] 王昕宇, 曾坚, “城市高温热浪灾害防灾规划策略研究——基于欧 美国家的规划经验”, 现代城市研究, 2017. No. 8: 84-92.

[23] 徐金芳, 陈敏, 邓振镛, “中国高温热浪危害特征的研究综述”, 干 旱气象, 2009. 27 (2): $163-67$.

[24] Smoyer-Tomic Karen E, Kuhn Robyn, “Heat Wave Hazards: An Overview of Heat Wave Impacts in Canada” , Natural Hazards, 2003. 28 (2): 465 - 86, https://doi.org/10.1023/A:1022946528157. 